\title{
Prevalence and Neighborhood Geomapping of COVID-19 in an Underserved Chicago Pregnant Population
}

\author{
Catalin S. Buhimschi, MD ${ }^{1}$ Gloria L. Elam, MD ${ }^{1}$ Stephen R. Locher, MD ${ }^{1}$ Doreen Norris-Stojak, RN ${ }^{2}$ \\ Hayfaa Aldasoqi, CNM ${ }^{2}$ Mary D. Stephenson, MD ${ }^{1}$ Irina A. Buhimschi, MD ${ }^{1}$ \\ ${ }^{1}$ Department of Obstetrics, Gynecology, University of Illinois College \\ of Medicine, Chicago, Illinois \\ 2 Patient Care Nursing Administration, University of Illinois Hospital \\ and Health Sciences System, Chicago, Illinois \\ Address for correspondence Catalin S. Buhimschi, MD, MMS, MBA,
Division of Maternal Fetal Medicine, Department of Obstetrics and
Gynecology, University of Illinois College of Medicine, 820 South
Wood Street (MC 808), Chicago, IL 60612 (e-mail: csb01@uic.edu).
}

Am J Perinatol Rep 2020;10:e413-e416.

\begin{abstract}
Keywords

- SARS-CoV-2

- COVID-19

- pregnancy

- racial disparity

Objective The Chicago area is known to harbor some of the deepest racial and ethnic socioeconomic inequalities in the United States. We studied the prevalence and neighborhood distribution of patients who tested positive for COVID-19 after implementation of universal screening at an academic hospital providing obstetrical services to an underserved Chicago population.

Study Design From April 16 to June 16, 2020, a total of 369 patients were screened for COVID-19 at University of Illinois at Chicago with either the Abbott Point-of-Care (POC, $n=266$ ) or reverse transcription polymerase chain reaction test (RT-PCR, $n=101$ ). Patient residential data mapped using ESRI ArcGIS Pro was integrated in ESRl's Living Atlas with the Neighborhood Socioeconomic Status Index (NSEI).

Results Precisely, 7.9\% (29/369) of screened patients tested positive; 69\% (17/29) with the POC test and 31\% (12/29) by RT-PCR. The prevalence of an outpatient RT-PCR positive result was $8.9 \%(9 / 101)$. All but one of the 29 severe acute respiratory syndrome coronavirus 2 (SARS-CoV-2) positive patients were either Hispanic or Black, and the majority resided in disadvantaged neighborhoods.

Conclusion The disproportionate hit of COVID-19 pandemic on the Hispanic and Black communities reflects in SARS-CoV-2 positivity rates in the obstetrical population. Our report provides data that may be useful to policy makers when prioritizing resources to communities in need.
\end{abstract}

Geographic differences in numbers of coronavirus disease 2019 (COVID-19) cases and deaths vary widely across the United States. The University of Illinois at Chicago (UIC) Hospital and Health Sciences System (UIH) serves as a referral site for the seriously ill throughout Chicago, which is the third most populous region in the United States. In response to the COVID-19 pandemic, on March 21, 2020,
Illinois Gov. J.B. Pritzker issued a stay-at-home order. ${ }^{1}$ To slow the spread of SARS-CoV-2, on April 16, 2020, UIC/UIH implemented a universal screening protocol for all women presenting for childbirth, management of high-risk antenatal or post-partum conditions, and for elective procedures. The SARS-CoV-2 prevalence in the U.S. pregnant population has ranged from 3.9\% (Connecticut) to 13.5\% (New York received

July 17,2020

accepted after revision

September 16, 2020
DOI https://doi.org/

10.1055/s-0040-1721416. ISSN 2157-6998.
Copyright $\odot 2020$ by Thieme Medical Publishers, Inc., 333 Seventh Avenue, 18th Floor, New York, NY 10001, USA Tel: +1(212) 760-0888.
License terms

()ㅇㅇ $\Theta \circledast$ 
e414 Prevalence and Neighborhood Geomapping in Pregnant Population Buhimschi et al.

City). No reports so far have focused on the Chicago area, which harbors one of the greatest racial, ethnic, and health care divides in the country. 2,3

\section{Methods}

From April 16 to June 16, 2020, a total of 369 patients were screened with either the Abbott Point-of-Care (POC) platform $(n=266)$ or RT-PCR $(n=103)$ using a standardized nasopharyngeal swab protocol. Patients scheduled for elective procedures were screened as outpatients. The diagnosis of mild-to-severe COVID-19 was established based on welldefined Centers for Disease Control and Prevention criteria. ${ }^{4}$ All patients had "persons under investigation" status, and full personal protective equipment was used until the results were reported. COVID-19 positive patients were delivered in designated rooms. Prospectively, collected demographic and clinical data were integrated with each subject's self-reported race, ethnicity, and residential address. The ESRI ArcGIS Pro (v2.5) with Living Atlas was used for neighborhood geomapping. The living neighborhoods of the catchment population were mapped using the Neighborhood Socioeconomic Status Index (NSEI) tool. ${ }^{5}$ The institutional review board concluded this analysis was not human subject research.

\section{Results}

During the study period, 366 patients were screened for SARSCoV-2 prior to admission, and 7.9\% (29/369) tested positive; $69 \%$ (17/29) with the POC and 31\% (12/29) with the RT-PCR platforms (- Table 1). The prevalence of an outpatient RT-PCR SARS-CoV-2 positive result was $8.9 \%$ (9/101). Total testing numbers reached their peak $(n=52 /$ week) 5 weeks postimplementation of the protocol (May 11-17, 2020).

Precisely, 62\% (18/29) of SARS-CoV-2 positive patients displayed mild-to-severe COVID-19 symptoms. The remaining $38 \%(11 / 29)$ were asymptomatic. Of the SARS-CoV-2 symptomatic patients, $31 \%$ (9/29) were admitted primary due to respiratory COVID-19 signs or symptoms. The other 69\% (20/ 29) presented to the hospital for obstetrical issues, and COVID19 was diagnosed upon admission by corroborating test positivity with present or past symptomatology (e.g., sore throat, headache, body aches, loss of smell, and/or gastrointestinal symptoms). Among SARS-CoV-2 negative patients only $1 \%$ (3/340) were admitted primary due to respiratory symptoms (chest pain and pulmonary edema), which in the context of negative viral workup remained of undetermined etiology.

The SARS-CoV-2 positive patients were younger, less frequently married, and more frequently had confounding symptomatology, which led to preeclampsia workup ( $p<0.05$ for all). All but one of the 29 SARS-CoV-2 positive patients (97\%) were either Hispanic or Black, and the vast majority resided in low socioeconomic neighborhoods (-Fig. 1). Predominantly Hispanic (e.g., zip 60608, 60609, 60623 ) or Black (e.g., zip 60827, 60644) neighborhoods accounted for $48 \%(14 / 29)$ and $38 \%(11 / 29)$ of SARS-CoV-2 positive patients, respectively.
Table 1 Demographic and clinical characteristics

\begin{tabular}{|c|c|c|}
\hline \multirow[t]{2}{*}{ Variables $^{a}$} & \multicolumn{2}{|c|}{ SARS-CoV-2 test result } \\
\hline & $\begin{array}{l}\text { Positive } \\
(n=29)\end{array}$ & $\begin{array}{l}\text { Negative } \\
(n=340)\end{array}$ \\
\hline Age $(y)^{b, h}$ & $25(22-30)$ & $29(24-34)$ \\
\hline Nulliparity ${ }^{\mathrm{c}}$ & $11(38)$ & $110(32)$ \\
\hline \multicolumn{3}{|l|}{ Marital status ${ }^{\mathrm{c}, \mathrm{h}}$} \\
\hline Married & $2(7)$ & $87(26)$ \\
\hline \multicolumn{3}{|l|}{ Race and ethnicity ${ }^{\mathrm{c}, \mathrm{h}}$} \\
\hline $\begin{array}{l}\text { White } \\
\text { non-Hispanic }\end{array}$ & $1(3)$ & $39(12)$ \\
\hline Black & $19(66)$ & $191(56)$ \\
\hline Hispanic & $9(31)$ & $65(19)$ \\
\hline Other & $0(0)$ & $45(13)$ \\
\hline \multicolumn{3}{|l|}{ Blood type ${ }^{c}$} \\
\hline $\mathrm{O}$ & $13(45)$ & $179(53)$ \\
\hline$A$ & $11(38)$ & $82(24)$ \\
\hline B & $5(17)$ & $57(17)$ \\
\hline$A B$ & $0(0)$ & $18(5)$ \\
\hline Unknown & $0(0)$ & $4(1)$ \\
\hline \multicolumn{3}{|l|}{$G A(w k)^{c}$} \\
\hline $\begin{array}{l}\text { First trimester: } \\
<14\end{array}$ & $3(10)$ & $23(7)$ \\
\hline $\begin{array}{l}\text { Second trimester: } \\
14-26\end{array}$ & $3(10)$ & $21(6)$ \\
\hline $\begin{array}{l}\text { Third trimester } \\
\text { preterm: } \\
27-36\end{array}$ & $8(28)$ & $52(16)$ \\
\hline $\begin{array}{l}\text { Third trimester } \\
\text { term: } \geq 37-40\end{array}$ & $15(52)$ & $239(70)$ \\
\hline Postpartum & $0(0)$ & $5(1)$ \\
\hline \multicolumn{3}{|l|}{ Hospital testing site ${ }^{c}$} \\
\hline OBER & $20(69)$ & $248(73)$ \\
\hline Outpatient clinic & $9(31)$ & $92(27)$ \\
\hline \multicolumn{3}{|c|}{ SARS-CoV-2 testing type ${ }^{c}$} \\
\hline $\begin{array}{l}\text { ID NOW point-of- } \\
\text { care Abbott }\end{array}$ & $17(69)$ & $248(74)$ \\
\hline $\begin{array}{l}\text { Central laboratory } \\
\text { RT-PCR }\end{array}$ & $12(31)$ & $89(26)$ \\
\hline \multicolumn{3}{|c|}{ COVID-19 symptoms severity ${ }^{c, d}$} \\
\hline Asymptomatic & $11(38)$ & \multirow[t]{3}{*}{ NA } \\
\hline Mild & $17(59)$ & \\
\hline Severe & $1(3)$ & \\
\hline Hypertension ${ }^{c, e}$ & $11(38)$ & $90(26)$ \\
\hline $\begin{array}{l}\text { Preeclampsia } \\
\text { workup }^{\mathrm{c} h}\end{array}$ & $13(45)$ & $88(26)$ \\
\hline \multicolumn{3}{|l|}{ Delivery mode ${ }^{c}$} \\
\hline Vaginal delivery & $13(44)$ & $210(62)$ \\
\hline Cesarean delivery & $7(24)$ & $79(23)$ \\
\hline
\end{tabular}


Table 1 (Continued)

\begin{tabular}{|c|l|l|}
\hline \multirow{2}{*}{ Variables $^{\text {a }}$} & \multicolumn{2}{|l|}{ SARS-CoV-2 test result } \\
\cline { 2 - 3 } & $\begin{array}{l}\text { Positive } \\
(\boldsymbol{n}=\mathbf{2 9})\end{array}$ & $\begin{array}{l}\text { Negative } \\
(\boldsymbol{n}=\mathbf{3 4 0 )}\end{array}$ \\
\hline Unknown $^{\mathrm{f}}$ & $9(31)$ & $51(15)$ \\
\hline $\begin{array}{l}\text { Neonatal SARS-CoV- } \\
2 \text { positive test }^{\mathrm{c}, \mathrm{g}}\end{array}$ & $0(0)$ & NA \\
\hline
\end{tabular}

Abbreviations: GA, gestational age; NA, not applicable; OBER, obstetrical emergency room unit; RT-PCR, reverse transcription polymerase chain reaction; SARS-CoV-2, severe acute respiratory syndrome coronavirus 2 .

aData analyzed using SigmaPlot (v12.5 Systat, San Jose, CA).

${ }^{\mathrm{b}}$ Data presented as median (interquartile range) and analyzed by Wilcoxon's rank-sum test.

'Data presented as no (\%) and analyzed by Chi-square test.

dPresence of illness and severity of COVID-19 was assessed clinically using the American College of Obstetricians and Gynecologists recommended algorithm with slight institutional modifications.

eDefined as blood pressure $\geq 140 \mathrm{~mm} \mathrm{Hg}$ (systolic) and/or $\geq 90 \mathrm{~mm} \mathrm{Hg}$ (diastolic).

${ }^{f}$ Accounts for ongoing pregnancies or transfer to care to other health care facilities.

${ }^{9}$ All newborns were for COVID-19 positive mothers were tested in the neonatal intensive care unit by RT-PCR.

$\mathrm{h}_{\mathrm{p}}<0.05$.

\section{Discussion}

Compared with other regions of the country, except New York City, this analysis identified a higher prevalence of positive SARS-CoV-2 test results in our underserved Chicago population than previously reported for another obstetrical population in Connecticut. ${ }^{3}$ The $7.9 \%$ test positivity identified in our institution is also higher than the 5.5\% positivity reported by the city of Chicago for the same time period. $^{6}$

Chicago has a long history of Black and Hispanic racial neighborhood segregation. ${ }^{7}$ The NSEI index tool showed that the vast majority of Chicago women in the UIC/UIH catchment area who tested SARS-CoV-2 positive were Hispanic or Black and resided in low socioeconomic status neighborhoods. Chicago minority populations are known to be disproportionally affected by the SARS-CoV2 pandemic, and our data suggest that this is reflected in COVID-19 positivity rates among obstetrical patients.

A positive COVID-19 test during pregnancy has important consequences. For patients who are symptomatic, there are obvious concerns related to maternal and fetal well-being due to the heightened state of inflammation and potential for diminished oxygen supply to the placenta and fetus. For patients who remain asymptomatic, COVID-19 positivity changes their pregnancy and delivery experience given the need of shielding the newborn from maternal exposure and of protecting the medical staff during patient-provider encounters. $^{8}$

Limitations of this study include the single institution and relatively short duration of analysis. Allocation of appropriate educational and financial resources to vulnerable pregnant populations residing in disadvantaged Chicago neighborhoods is needed.
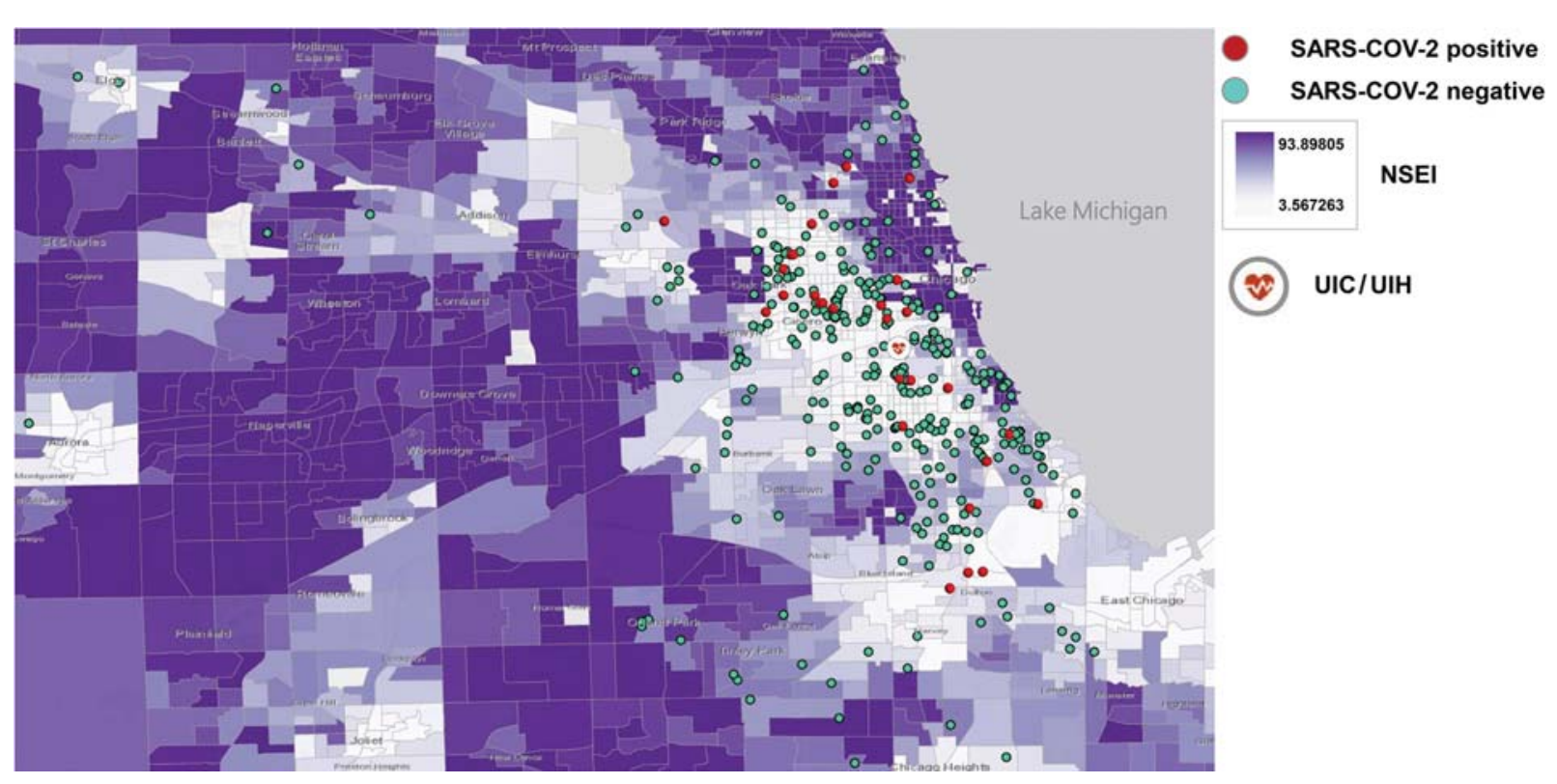

Fig. 1 Overlay of the screened population with the NSEI. The NSEI varies from 0 to 100 . A score of 50 represents the national average. NSEI incorporates the median household income, percent households with income below the Federal Poverty Line, educational attainment of adults (age $25+$ ), rate of unemployment, and percent of households with children under the age of 18 that are "female headed" (no male present). Data for NSEI come from the U.S. Census Bureau 2011 to 2015 American Community Survey as implemented in ArcGIS's Living Atlas. Original map scale 1:400,000. Areas intensely purple have high NSEl and white areas have low NSEI. NSEI, Neighborhood Socioeconomic Index; UIC/UIH, University of Illinois at Chicago/ Hospital and Health Sciences System. 
e416 Prevalence and Neighborhood Geomapping in Pregnant Population Buhimschi et al.

\section{Authors' Contributions}

C.S.B. had full access to all of the data in the study and takes responsibility for the integrity and accuracy of data analysis. C.S.B, L.G.E., S.R.L., D.N.S., H.A., M.D.S, and I.A.B. supported in conceiving the concept and design, and performed analysis or interpretation of data. H.A., I.A.B., and C.S.B. involved in data collection. I.A.B. and C.S.B. dedicated in drafting of the manuscript and statistical analysis. C.S.B, L.G.E., D.N.S., S.R.L., and M.D.S coordinated in supervision. All authors carried out the critical revision of the manuscript for important intellectual content.

\section{Conflict of Interest}

None declared.

\section{References}

1 https://www.illinoispolicy.org/pritzker-orders-illinoisans-toshelter-in-place-until-april-7/
2 Sutton D, Fuchs K, D’Alton M, Goffman D. Universal screening for SARS-CoV-2 in women admitted for delivery. N Engl J Med 2020; 382(22):2163-2164

3 Campbell KH, Tornatore JM, Lawrence KE, et al. Prevalence of SARS-CoV-2 among patients admitted for childbirth in Southern Connecticut. JAMA 2020;323(24):2520-2522

4 Symptoms of Coronavirus Accessed 2020https://www.cdc.gov/ coronavirus/2019-ncov/symptoms-testing/symptoms.html

5 Miles JN, Weden MM, Lavery D, Escarce JJ, Cagney KA, Shih RA. Constructing a time-invariant measure of the socio-economic status of U.S. census tracts. J Urban Health 2016;93(01):213-232

6 COVID Dashboard Queried on August 3 for period April 16, 2020 to June 16, 2020 at https://www.chicago.gov/city/en/sites/covid-19/ home/covid-dashboard.html

7 Matoba N, Reina M, Prachand N, Davis MM, Collins JW. Neighborhood gun violence and birth outcomes in Chicago. Matern Child Health J 2019;23(09):1251-1259

8 Stanojević M. Are Covid-19-positive mothers dangerous for their term and well newborn babies? Is there an answer?. J Perinat Med 2020;48(05):441-445 